\title{
RESUMO
}

EDUCAÇÃO

V.8 $\cdot$ N.2 $\cdot$ Março -2020

ISSN Digital: 2316-3828

ISSN Impresso: 2316-333X

DOI: 10.17564/2316-3828.2020v8n2p189-204

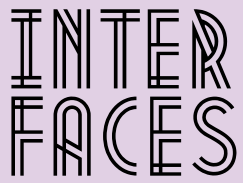

CIENTÍFICAS

\section{POLÍTICAS DE NARRATIVIDADE E PERFOMANCES DE GÊNERO NA ESCOLA: CARTOGRAFIAS EM ABERTO}

POLITICS OF NARRATIVITY AND GENDER IN SCHOOL: OPEN CARTOGRAPHIES

\section{POLITIICA DE NARRATIVIDAD Y GÉNERO EN LA ESCUELA: CARTOGRAFÍAS ABIERTAS}

Lucemberg Rosa de Oliveira ${ }^{1}$ Ana Lúcia Gomes da Silva ${ }^{2}$ Juliana Cristina Salvadori ${ }^{3}$

\section{DOSSIÊ:}

"CORPO, GÊNERO E SEXUALIDADE NA CIBERCULTURA: MODOSDE CONHECER, PRÁTICAS DE SOCIABILIDADE E REDES EDUCATIVAS"
As cartografias mapeadas neste artigo tomam como centralidade as categorias gênero, práticas pedagógicas e formação docente, na tentativa de responder como gênero está presente na escola e de que maneira atravessa as práticas dos/a professores/a. A pesquisa, tecida colaborativamente com sete participantes, se ancora na abordagem qualitativa, utilizando como procedimento de construção e de análise o método cartográfico, tendo em vista a perspectiva pós-crítica de questionar os próprios modos de fazer pesquisa em educação. Como dispositivos de construção dos dados, utilizamos os Ateliês de Pesquisa e observação participante, buscando registrar por meio do diário de bordo algumas situações do cotidiano escolar para problematizar e refletir sobre as práticas e, consequentemente, formar professores/a em exercício para o trato com a temática. Como resultado foi possível perceber que muitos/a professores/a ainda se sentem reféns de práticas pedagógicas incoerentes com as demandas dos sujeitos da contemporaneidade, presentes na escola. Outro dado evidenciado aponta que a escola ainda é regida por uma estrutura hierárquica que insiste em olhar mais para a normatividade do que para a diversidade.

\section{PALAVRAS-CHAVE}

Gênero. Práticas Pedagógicas. Diversidade. Cartografia. Professores em exercício. 


\section{ABSTRACT}

The cartographies mapped in this paper consider gender, pedagogical practices and teacher education as their core concepts. It attempts to answer how gender differences/issues impact on teacher's practices. The qualitative research, founded on a postcritical perspective in education, was carried out with seven participants and is based on cartographic method as procedure of data construction and analysis. Research Atelies and participant observations were used as data gathering/construction techniques, as well as a logbook, to register, problematize and reflect on everyday situations, thus providing in-service on the theme education for teachers. The findings point out that many teachers feel they have been hold hostage by pedagogical practices mismatched with demands brought to school by contemporary subjects. Also, data shows that schools are still governed by a hierarchical structure which insists on promoting a privileged view of norms and normality to the detriment of diversity.

\section{KEYWORDS}

Gender. Pedagogical practices. Diversity. Cartography. In-serviceteachers.

\section{RESUMEN}

Las cartografías mapeadas en este documento consideran el género, las prácticas pedagógicas y la formación docente como sus conceptos centrales. Intenta responder cómo las diferencias/ problemas de género afectan las prácticas de los docentes. La investigación cualitativa, fundada en una perspectiva poscrítica en educación, se realizó con siete participantes y se basa en un método cartográfico como procedimiento de construcción y análisis de datos. Los talleres de investigación y las observaciones de los participantes se utilizaron como técnicas de recopilación/construcción de datos, así como un libro de registro, para registrar, problematizar y reflexionar sobre las situaciones cotidianas, proporcionando así una educación en el tema para los maestros. Los resultados señalan que muchos maestros sienten que han sido tomados como rehenes por prácticas pedagógicas que no coinciden con las demandas presentadas por los sujetos contemporáneos en la escuela. Además, los datos muestran que las escuelas aún se rigen por una estructura jerárquica que insiste en promover una visión privilegiada de las normas y la normalidad en detrimento de la diversidad.

\section{PALABRAS CLAVE}

género. Prácticas pedagógicas. Diversidad. Cartografía. Profesores en servicio. 


\section{PISTA INTRODUTÓRIA}

0 presente artigo apresenta tensionamentos às discussões sobre performances de gênero e práticas pedagógicas de professores(as) de uma Escola da Rede Municipal de Barra do Mendes-BA. A pesquisa, realizada no Mestrado Profissional em Educação e Diversidade (MPED) 4 da Universidade do Estado da Bahia (UNEB), foi tecida colaborativamente com sete participantes: cinco professores/as, o coordenador pedagógico e o gestor da instituição. Considerando as dimensões éticas da pesquisa optamos por usar nomes fantasia para preservar a identidade dos colaboradores e colaboradoras da pesquisa, assim como a de um estudante, que chamaremos de Michel.

Para a escolha do(a)s participantes consideramos o princípio da heterogeneidade: idade, tempo de serviço, orientação sexual, áreas de conhecimento e funções/cargos na instituição (direção, coordenação pedagógica e corpo docente). Essa diversidade oportunizou trazer para os debates as itinerâncias de cada um/uma sobre a temática no variado território escolar.

A pesquisa se ancora no horizonte qualitativo, utilizando o método cartográfico para apontar epistemológica e metodologicamente o processo de construção e análise dos dados. A perspectiva pós-moderna, pós-crítica e pós-estruturalista adotada questiona os próprios modos de fazer pesquisa e permite ao pesquisador não se prender ao formalismo metodológico, mas criar, experimentar e produzir a pesquisa como princípio educativo, cognitivo, formativo, colaborativo e de reflexão/avaliação da prática pedagógica.

Dentre os dispositivos de construção dos dados destacamos: Ateliês de Pesquisa e observação participante, registrados em diário de bordo. Nossa escolha pela concepção de dispositivos na pesquisa realizada foi inspirada nos estudos de Deleuze (1996), pois os concebe como meadas com fios de naturezas distintas que, lançados em campo, tomam contornos heterogêneos diante do objeto de estudo. Tendo em vista esses preceitos, operacionalizamos as narrativas por meio dos Ateliês de Pesquisa (AP) de modo a traçar mapas em aberto, que podem ser rasgados, revertidos, e adaptados a montagens de qualquer natureza, para um indivíduo, um grupo, uma formação social.

Partimos do pressuposto teórico de Ateliê de Pesquisa a partir dos autores Filho (2016) e Filho e Silva (2015) que destacam nesse dispositivo a construção coletiva de dados num espaço formativo que toma o cotidiano escolar para problematizar e refletir, coletivamente, sobre as práticas, bem como formar professores/as em exercício para o trato com a temática, tornando-nos, com nossos colaboradores, cartógrafos, no movimento de nos por em análise por meio de nossas práticas pedagógicas.

No Ateliê de Pesquisa dialogamos com o conceito de prática pedagógica apresentado por Franco (2016), ao nos afirmar que as práticas pedagógicas dos docentes são ferramentas centrais para pesquisa em educação, pois, sendo intencionais, devem considerar os contextos e os sujeitos cujos saberes são experienciados em sua produção cotidiana da existência, entrelaçando vida e solidariedade no movimento da prática didática.

4 Este trabalho emerge da pesquisa de mestrado intitulada: Dissidências e (im)pertinências de gênero no território escolar: memorial cartográfico desenvolvida num Programa de Pós-Graduação de uma instituição pública do Estado da Bahia, cujo objeto de estudo foram as performances de gênero e como estas se manifestam nas práticas pedagógicas de uma escola municipal do interior baiano. Teve como orientadora a Dra. Ana Lúcia Gomes da Silva. 
Nos encontros realizados com os docentes, gestores e coordenadores pedagógicos, a centralidade era a reflexão sobre as práticas pedagógicas, os silêncios prenhes de sentidos, interditados, latentes, quando o assunto era gênero, sexualidade, raça/cor etc.

A pergunta central do coletivo docente e nossa como pesquisadores era: como dialogar com as questões de gênero e sair do silêncio para a transgressão? Assim, as narrativas dos sujeitos foram cartografadas, construindo assim uma "cadeia de significantes que estrutura formas cognitivas de representar o mundo e compartilhar a realidade social, ao mesmo tempo em que engendra sonhos e desejos, mitos e utopias" (PÉREZ, 2002, p. 55).

A partir dessas pistas, desenvolvemos as cartografias mapeadas neste artigo, organizando-o em duas seções: a primeira destinada a explicitar o silenciamento da escola frente às questões de gênero e a segunda apresenta as questões mapeadas, em estado de ebulição, transgredindo a suposta normalidade que ainda rege na escola.

\section{PISTA DOIS: AS CARTOGRAFIAS DE GÊNERO NA TESSITURA DA DIVERSIDADE}

Nossa filiação teórica acerca da diversidade é ancorada nas diferenças, em que a diversidade é entendida como construção histórica, social, cultural e política as quais se realizam em meio às relações de poder e ao crescimento das desigualdades de várias ordens, devendo ser combatidas no âmbito da escola e fora dela, já que defendemos uma escola plural, cidadã.

Utilizamos esses conceitos a partir do diálogo com Rios (2015), Ivenicki (2015), Silva (2015), Moreira e Candau (2008), Candau (2012), Canen (1999; 2001), compreendendo-os como marcadores de um campo teórico híbrido que tem se constituído em um movimento de reconhecimento e valorização da diversidade cultural e, logo, de novas identidades em uma sociedade que é múltipla, fragmentada, principalmente, plural. Essa compreensão não permite, portanto, que a diversidade e as diferenças sejam traduzidas como desigualdades, fórmula usada para despotencializar as vozes e narrativas plurais que habitam distintos territórios, inclusive a escola.

Quando passamos a enxergar a escola com as lentes de pesquisadores, atravessamos as barreiras e limites hegemônicos e normativos definidas pelos dentro/fora/fora dentro, como nos convida Nilda Alves (2001), de modo a mostrar a diversidade ali presente. Este compromisso se reveste de desafios éticos que engendram as nossas cartografias em campo, sobremaneira no trato com temas considerados interditados na escola. Um dos desafios foi posto pela fala do colaborador Pablo (2018):

Essa questão de gênero mesmo está por toda parte gente, não vê agora, estudando para o concurso do estado é um dos temas mais explorados... É porque a gente não presta atenção e também tem outro negócio fica muito ruim de se trabalhar primeiro porque ainda são meninos e depois... depois a formação, vei, pega bastante a gente fica com dificuldade. (Informação verbal).

Aqui, vemos claramente como a temática gênero gera incômodo e dificuldades, marcados pelo docente pela idade dos/as alunos/as e, num segundo momento, pela formação, outro eixo central da 
nossa pesquisa. Ao longo dos Ateliês de pesquisa também se evidenciam outras narrativas, de docentes, coordenadores e gestores, sobre as contradições e equívocos que os termos/conceitos gênero e sexualidade, muitas vezes considerados sinônimos, engendram.

Segundo Miskolci (2016), nosso desafio como parte integrante da escola "perpassa por superar a pedagogização do sexo e transformar a posição da escola não mais como subserviente aos interesses estatais e biopolíticos, mas comprometer-se com as demandas da sociedade civil [...]" (MISKOLCI, 2016, p. 16). Por isso é tão importante repensarmos a educação pela ótica das minorias, dos abjetos, ignorados por tanto tempo e, assim, superar injustiças e desigualdades:

A gente precisa pensar no processo que o respeito é um valor construído. Infelizmente na sociedade, há supremacia de um grupo sobre o outro. Eu acho que a gente precisa trabalhar aos poucos com isso para tentar mudar mesmo a mentalidade, a cabeça. Se a gente for ficar formado discurso e mais discursos isso vira uma bola de neve tão grande [...]. (LIA, 2018, informação verbal)

Louro (2014, p. 61) aponta que "[a escola] incumbiu de separar os sujeitos dos outros, tornando aqueles que nela frequentavam distintos dos que não frequentavam". Essa realidade começa a se modificar paulatinamente com a inserção de grupo populares na escola, porém, ainda é uma fronteira a ser transposta, a da verdadeira inclusão. Para tanto,

[...] é indiscutível trabalhar na escola por meio das pedagogias culturais que valorizem o respeito e à busca de mecanismos e estratégias analíticas, metodológicas que visam o tratamento e a superação das desigualdades de gênero nos processos de desenvolvimento, bem como os processos subjacentes a essas desigualdades, persistentes em nossa sociedade. (ALVES et al., 2010, p. 7).

A professora, em sua fala, reconhece o papel da escola na construção de valores hegemônicos que garantem a supremacia de grupo sobre outros. Contudo, na fala da professora sobre questões de gênero há uma ambiguidade: conquanto ela enfatize que precisamos sair do campo dos discursos para promoção ações ela destaca que isso precisa ser aos poucos, então não há defesa da ruptura, mas sim o medo desta ruptura, do debate se tornar uma "bola de neve tão grande". A docente faz o apelo de ir aos poucos para poder mudar mesmo a mentalidade, a cabeça. Existe aí uma ambiguidade: falar menos e fazer mais; falar menos para não gerar conflito; mudar, mas ir aos poucos.

Como nos mostra Butler (2016, p. 235), os discursos fabricados por diferentes meios e instrumentos como família, amigos, escola e outros controlam as fronteiras normativas de gênero e intimidam os sujeitos que participam desse processo, visto que "a realidade [...] é efeito e função de um discurso decididamente social e público”. Durante as observações participantes, registradas no diário de bordo, pudemos evidenciar um caso que exigia de nós verdadeira atenção quanto a esses discursos e suas fronteiras.

Tratava-se de um aluno que estava passando por situações relativas à aceitação de sua identidade de gênero tanto de sua parte como de sua família. Professores e direção relataram momentos difíceis no convívio com este adolescente, principalmente na sua chegada à instituição. 
Dentre as questões emergentes destacamos: como esse aluno vê a escola e seu lugar neste espaço, considerando sua identidade de gênero? Por meio dessas observações tivemos acesso à informação de que esse estudante materializava seus sentimentos em relação às questões de sua identidade de gênero por meio do corpo, utilizando piercings, corte e cor de cabelo tidos como exóticos, além de performances em sala (e fora dela) que iam da sensualidade/sexualidade à auto mutilação. 0 relato foi feito ao pesquisador após o II Ateliê de Pesquisa por um dos profissionais:

[...] Olha o caso de Michel, já tem uns dias que venho observando que ele fica ali parado, sentado na dele, as colegas tentam animá-lo. Ano passado ele ficou assim também, mas não dávamos muita importância e o que aconteceu foi a automutilação decorrente de situações com briga com a mãe por causa da sua sexualidade, agora a gente fica mais atento né, pra isso não acontecer de novo. (RICO, 2018, informação verbal).

Outro profissional se aproximou e explicou que situações de automutilação tinham sido muito presentes no ano anterior, mas que a de Michel exigia certa cautela porque a escola acreditava ser fruto da sua orientação sexual. Ficamos a observar durante uns quatro minutos, então sugeri que 0 melhor era conversar com o professor RuPaul 5 .

Chamamos o professor para o diálogo e ele afirmou que dialoga com o aluno pelo whatsapp, inclusive este havia the narrado o processo de contar aos pais sobre sua sexualidade. Relatei então que observara Michel na porta da sala de aula e sua expressão de tristeza. O professor contou-nos que esta tristeza advinha da situação conflitante com os pais e que estes iriam mudar para São Paulo, algo que não agradara ao garoto.

O diálogo continuou e o professor nos narrou que Michel se sente invisibilizado na escola, uma vez que os outros professores e professoras não têm esse momento de escuta sensível. Esse fato veio ao encontro de algo já dito pelo diretor em sua narrativa, quando nos relatou a fala de educadores/ as após a escolha do aluno para líder de sala. Muitos não aprovaram por considerar Michel um aluno parado, sem autoestima, muito "deprê" - até usaram o termo morto-vivo - em sala de aula. Infelizmente, a conversa não durou mais de dez minutos por conta do horário de aula, mas foi o suficiente para tensionar conflitos internos do professor pesquisador e, diante de algumas outras situações, motivou-nos a trazer a situação para discussão no Ateliê de Pesquisa.

Com isso, nos perguntamos, durante o campo, quantos Micheis habitam a escola como um espaço disciplinador, inclusive de identidades, que nem sempre agencia os conflitos e, ainda, nega ou silencia a existência de outros gêneros não normativos?

O que percebemos no caso de Michel no que tange à escola e a sua política de narratividade sobre sua identidade de gênero é "um conjunto repetido de atos no interior de uma estrutura reguladora, altamente rígida, os quais cristalizam no tempo para produzir a aparência de uma substância, uma classe natural de ser" (BUTLER, 2016, p. 56). Mas mesmo nesse espaço já tão normatizado a diferença

5 Este professor leciona os componentes curriculares Português e Redação na turma de Michel. É homossexual com identidade de gênero aberta a toda sociedade. Além da docência, exerce a função de técnico de enfermagem e está cursando bacharelado na área. Por esse motivo não teve espaço em sua agenda para participar diretamente de nossa pesquisa. 
emerge - os participantes afinal sinalizam o conflito - do aluno e seu - no que tange a sua performance fora e dentro da escola e aí há a potência da escola.

Neste sentido, a homossexualidade subverteria a norma, a partir da ocupação, no caso da homossexualidade masculina, de uma posição inferior (dominada) (BOURDIEU, 1999; BOZON, 1999). Essa posição foi construída historicamente, pela medicina e psiquiatria, a partir da reelaboração da prática homossexual como enfermidade, portanto, lidar na escola com estes sujeitos considerados excêntricos, interrogam a docência e interpela os sujeitos, cujas tensões e respostas, só são possíveis serem gestadas no estudo junto ao coletivo, na escuta, no afeto sem julgamentos, de modo a humanizar as práticas pedagógicas por nós praticadas no território existencial da escola.

\section{ENTRE A TRANSGRESSÃo E A DISCUSSÃO NA PRÁTICA: LINHA TÊNUE}

Cumpre-nos apresentar o conceito de transgressão inspirados nos estudos de Bell Hooks (2013). Ela aponta que adotou os seguintes paradigmas pedagógicos ${ }^{6}$ : afeto, autonomia, educação libertadora, esperança, de Paulo Freire, que dialoga de modo consubstancial com a pedagogia feminista como modelo que rompe silêncios, fronteiras, ensina a pensar, ousar, falar, em síntese, ensina a transgredir e que, pelo viés da amorosidade, se faz encarnado e vivo, promove o empoderamento e a leitura crítica do mundo onde se insere. A autora afirma ainda que "[...] o poder de ensinar é um ato de resistência que se contrapõe ao tédio, desinteresse e apatia onipresentes que tanto caracterizam o modo como professores e alunos se sentem diante do aprender e ensinar, diante da experiência da sala de aula" ( HOOKS, 2013, p. 21).

Destacamos, nesse contexto em que as tensões se materializam no território escolar, dois momentos narrados pelas colaboradoras da pesquisa que dialogam com esses pressupostos, o primeiro de Aretusa, quando, no Ateliê eles/as foram questionados se dentro da escola havia situações diretas ou indiretas que reforçavam práticas machistas, a resposta em coro foi que não. Então direcionamos para um fato específico para ver se esta resposta mudava, então mostramos a foto do Banner de entrada que parabeniza alunos(as) aprovados na seleção do Instituto Federal de Educação, Ciência e Tecnologia da Bahia (IFBA). Então a nossa colaboradora diz o seguinte:

Ah. Eu percebi isso aí, percebi que só tinha Davi, de homem, tinha muito mais alunas do que alunos, mas como a gente foi educado [Lia complementa: machismo mesmo], então voltando, e a gente foi educado, tipo, na escola que seria assim que quando tivessem homem você deveria generalizar a fala. É algo genérico. (ARETUSA, 2018, informação verbal).

6 Em 'Ensinando a transgredir', Bell Hooks - escritora, professora e intelectual negra insurgente - escreve sobre um novo tipo de educação como prática da liberdade. Para ela, ensinar os alunos a "transgredir" as fronteiras raciais, sexuais e de classe a fim de alcançar o dom da liberdade, é o objetivo mais importante do/a professor/a. Para maior aprofundamento ver a referência completa da obra de Bell Hooks ao final do texto. 
A performance continua sendo reforçada na narrativa expressa pela docente: "fomos educados assim" ao dizer que quando há meninos e meninas a tendência é usar o chamado genérico na referência, que é masculina. Este dado nos provoca e nos ensina, pois todos e todas ratificamos e legitimamos discursos que estereotipam e naturalizam o que não é natural. Quando no coletivo refletimos acerca das nossas práticas, nos deslocamos ao ler o que narramos - esta é a potência.

0 docente Rico complementa esta fala de modo sucinto: "precisamos reaprender a falar e mudar nossas atitudes, parar de usar tudo no masculino para se referir as mulheres". A mudança nesse percurso na escola depende de nossas práticas, uma vez que, quando estamos dispostos a alterar essas estruturas hegemônicas, o primeiro passo é a compreensão destas e sua agência. 0 que aprendemos ao cartografar e nos pôr em análise, imersos na escola, é que não basta pregar transformações se estas não forem resultantes deste movimento reflexivo que nos reeduca.

A professora Linniker (2018), retomando ao ponto anterior, cujos discursos reforçam as práticas normatizantes de perfomantividade, contou-nos uma situação de uma cena familiar com seu filho, aproveitando que no AP discutimos que as performances também têm a ver com o falar, maneiras de agir, expressões etc.:

Essa questão aí da voz, né? Lá em casa eu estou sofrendo com isso, porque eu estou cobrando de mais do meu filho, né? Pois é, é justamente por isso, porque ele está com uma voz fina e eu fico assim, meu filho qual o motivo dessa voz? E ele responde: "Ah! Mainha... (risos). Lia tenta descontrair a situação dizendo: "lá em casa todo mundo tem a voz grossa”. Todos os presentes riem, então Linniker retoma: Assim, pesquisando eu fui ver, mas é uma coisa que a gente fica preocupada enquanto mãe né? De não ver a hora que ele vai começar engrossar a fala. (falas mútuas "olha o preconceito" risos). (LINNIKER, 2018, informação verbal).

Linniker não consegue mais retomar a fala. As narrativas se alternam e há muitos risos nesse momento. Neste caso, para além do discurso normatizador da performance de gênero, também verificamos como agem as imposições dos papéis de gênero, responsáveis por estabelecer padrões circunscritos capazes de definir ou não o que é ideal de cada gênero.

Aqui Linniker precisou se desterritorializar para aceitar a ideia que seu filho no futuro poderá ou não ter a voz fina, cujo plano de força, nesse caso é caracterizado pela normatização do gênero, uma vez que, ao homem é atribuída a voz grossa, argumento este não enveredado por Lia. Conforme Garcia (2011, p. 137), "O modo de vivenciar e expor performance e diversidade perpassa pelo corpo e a leitura de sua contextualização”. Ou seja, o fato de ter voz fina pode ser caracterizado como exemplo de performance de gênero.

Na visão de Louro (2016, p. 23), "não há como ignorar as novas práticas, os novos sujeitos e suas contestações ao estabelecido", mas, para que isso aconteça, repensar a escola como espaço plural requer de nós entender que somos parte desse processo e que de nada adianta atribuir funções a ela se nós somos os agentes tão necessários para a mudança. Por isso, quando se fala em discutir as questões de gênero no espaço escolar, muitos (pré)conceitos são estigmatizados e impendem-nos de 
proporcionar debates fecundos e levem a uma verdadeira transformação que (des)cubra e (des)nude os vestígios de cultura misógina e patriarcal que ainda se faz presente.

Mas, para alcançar esse resultado de (des)cortinar os preconceitos, alguns questionamentos são necessários. Primeiramente, compreendemos a escola como um espaço plural de manifestação das diversidades? Como professores/as, diretores, técnicos, auxiliares e demais participantes quem compõem o corpo de escola estamos abertos à mudança? Admite-se invisibilizar os sujeitos por causa de seu gênero? Essas pistas, ou melhor, questionemos começaram a surgir a partir de uma informação verbal propagada pela colaborara Linniker (2018) durante a realização do $3^{\circ}$ ateliê quando os presentes foram perguntados quem é esse novo/diferente que tem adentrado no cotidiano da escola? Será que só pode considerar diferente por causa de sua identidade de gênero?

Essa semana eu me deparei com uma situação que eu não soube o que fazer, eu não soube responder ao aluno. Um aluno do sétimo ano, ele chegou pra mim e falou que precisava de ajuda. Ele disse assim: eu preciso me descobrir, eu não sei se gosto de homem ou gosto de mulher. [Vozes ecoaram: Orra!] Aí o que que aconteceu, eu fiquei assim oh! Sem saber o que dizer. Eu não tive ação no momento. A única coisa que eu respondi para o aluno foi "realmente, tá difícil”. Aí eu falei e por que essa descoberta agora? Ele respondeu: 'Ah! Professora é porque eu já fiquei com mulher e fiquei com homem'. Aí fui e disse: 'o que é que você achou melhor?' Ele respondeu que achou melhor o homem. Aí fui e disse: 'E você precisa do que então? 0 aluno respondeu que a mãe e o pai não aceitavam. (LINNIKER, 2018, informação verbal).

Nesse contexto da narrativa da colaboradora, encontramos como Plano de Força que sustenta o não transgredir de fronteiras, a questão do gênero dominante imposta por uma série de padrões instituídos socialmente e que vêm sendo perpassada por instituições sociais como família, igreja, e, a própria escola. Conforme nos mostra Connell (1995, p. 198):

Os rapazes são pressionados a agir e a sentir dessa forma e a se distanciar do comportamento das mulheres, das garotas e da feminilidade, compreendidas como o oposto. A pressão em favor da conformidade vem das famílias, das escolas, dos grupos de colegas, da mídia e, finalmente, dos empregadores. A maior parte dos rapazes internaliza essa norma social e adota maneiras e interesses masculinos, tendo como custo, frequentemente, a repressão de seus sentimentos.

Observamos neste contexto que o Plano de Forças está agindo para manter o que poderia ser chamado de normalidade. Também, na narrativa de Linniker, podemos observar nos elos de angústia da professora, o desejo de mudança, identidade de gênero descortinada. Todavia, é importante ressaltar que, deparar com uma situação dessas como a retratada por ela não é nenhuma novidade, uma vez que muitos alunos têm buscado mais apoio nos educadores do que na família, mas a angústia descrita por não saber como reagir diante do aluno, causa-nos, de certa forma, mais angústia do que o já retratado pela docente, o que evidencia cada vez mais a necessidade de uma formação em exercício, que trate a temática com a relevância que esta exige. 
Por isso, o convite urgente que nos chega é para repensar nossas práticas, tornando o espaço escolar num espaço para promoção e transformação social a partir das diferenças. Não é recente que as questões de gênero vêm invadindo os muros do lócus onde realizamos a pesquisa, uma vez que em alguns momentos, no decorrer da pesquisa, alguns colaboradores evidenciaram isso. Uma delas foi Aretusa.

Com relação aquele nosso aluno do ano passado, já melhorou, como eu conversei com vocês. A mãe veio chorar e tudo, falando pra mim, que o filho era trans isso e aquilo, só que ela interpretou de uma outra forma, na verdade ele não é trans, ele não soube dizer pra ela o que ele era, até pelo fato de como ela descobriu. Ela descobriu por meio de uma mensagem do celular que a irmã pegou e tal e fez todo aquele reboliço e tal. Ele veio conversar comigo na época, mas na verdade ele veio perguntar o que a mãe tinha conversado, se foi a respeito desse assunto. Aí eu falei que não, que não tinha nada a ver, aí eu fui e falei por quê? Você sente necessidade de conversar sobre isso? Aí ele foi e falou não, professora, é porque realmente eu tô com dúvida, eu não sei o que é que eu quero. Eu tenho 14 anos e ainda não sei o que eu sou, porque eu converso com pessoas do mesmo sexo e eu me identifico, já troquei fotos, já troquei vídeos, eu gosto demais, só que a forma como a minha mãe me tratou eu não sei se eu posso seguir adiante, ou seja, de certa forma ele sentiu confiança em falar disso pra mim e possa ser... possa ser que não. Foi um caso no qual ele queria abertura da mãe e não conseguiu, porque a mãe já chegou pedradas. (ARETUSA, 2018, informação verbal).

É válido ressaltar que os alunos necessitam conviver com a diversidade, porém, como menciona Facioli (2015, p. 45): "[...] a escola pode se consolidar como um lugar acolhedor, ou pode se converter num ambiente onde se reproduzem preconceitos, silêncios e formas de discriminação". Em consonância ao que traz Facioli, a pesquisadora Berenice Bento (2008, p. 555) nos explica que: "a escola, que se apresenta como uma instituição incapaz de lidar com a diferença e pluralidade funciona como uma das principais instituições guardiãs das normas de gênero e produtora da heterossexualidade", uma vez que os seus membros são frutos dessa sociedade preconceituosa formada por indivíduos que se movimentam no âmbito social atrás de inúmeras máscaras que tem o objetivo de satisfazer os olhares do outro.

Como educadores/as, nosso desafio é realizarmos observações e leituras atentas do cotidiano escolar, ou melhor, como dizem (SILVA; SOUZA; TEIXEIRA FILHO, 2015), basta ler a escola, seus sujeitos e suas ações que engendram mulheres e homens, que perceberemos a escola como um microcosmo social, no qual as relações sociais produzidas no ambiente além-escola se (re)produzem.

É exatamente por ressoar em nós a proposta apresentada por Margareth Rago sobre o gênero na nova escola (2003), que buscamos, ainda que de forma limitada e inicial, uma prática pedagógica que nos desafia a buscar constantes diálogos com colegas de profissão que discutem as categorias supracitadas em seus trabalhos de pesquisa e estudos. Assim, esses aspectos não são diferentes quanto à etnia/raça em que a primazia de uma delas, a branca, define quem tem mais privilégios e oportunidades, são melhores tratados, são belos, se enquadram no modelo padrão de inteligência, racializando de forma continuada meninos e meninas negras, que não se reconhecem no currículo da escola, pois são invisibilizados e silenciados. 


\section{4 “NINGUÉM SOLTA A MÃO DE NINGUÉM"7: CONCLUSÕES COLABORATIVAS}

A expressão entre aspas destacada neste subtítulo diz muito sobre o nosso lugar de fala como homens e mulheres que lutam por dias melhores e que acreditam que a educação só promoverá uma nova base conceitual e epistemológica capaz de lidar com todas as diversidades a partir do momento em que a heterogeneidade que nos forma estiver como fundamento de nossas práticas pedagógicas.

Isso significa para Desgagné (2007) a construção de conhecimentos ligados a uma dada prática profissional deve considerar o contexto real em que ela é atualizada e os seus componentes, em termos de limites e recursos existentes em situações reais, observando em que contribuem para a sua estruturação.

Os dados empíricos apresentados tecidos às nossas reflexões destacam problemáticas que emergem no campo de atuação de profissionais da educação inquietados com os contextos desafiadores dos territórios que habitam, dentre eles resumir os desafios segundo os teóricos que usa e o que encontrou.

A pesquisa engajada ${ }^{8}$ que originou este artigo se funda na ética e episteme de que a partir da reflexão, análise e avaliação de nossas práticas que podemos construir, colaborativamente, estratégias concretas, integradas, inclusivas, que possam traduzir, isto é, mediar, diálogos sobre aprendizagens e formação - sobre si, sobre o outro, sobre as fronteiras e interditos e sobre e transgressões fundadas numa prática libertadora. Como coloca Silva e Sá (2016, p. 125),

A colaboração implica em trabalho conjunto, pois ao trabalharem juntos, os membros de um grupo se apoiam visando atingir objetivos comuns negociados pelo coletivo estabelecendo relações que tendem a não hierarquização, à liderança compartilhada, à confiança mútua, e à corresponsabilidade pela condução das ações.

Esse processo para construção da pesquisa no âmbito de um Mestrado Profissional que toma Educação e Diversidade como seus fundamentos nos desafia, pois, falar da lógica processo, produto, intervenção e da potência dos ateliês como dispositivo que tece rede colaborativa para empoderamento dos sujeitos e suas experiências aliadas aos saberes do contexto escolar. Retomar educação na perspectiva multicultural e diversidade da filosofia da diferença.

Nessa perspectiva ocorreu a construção do projeto didático-pedagógico, uma das atividades formativas propostas. 0 projeto foi finalizado durante o penúltimo Ateliê, em 12 de abril, sendo retomado e socializado em 19 de abril de 2018. Decorrido esse processo, cada um dos presentes contribuiu para a estruturação dele - o protagonismo dos colaboradores nesse processo formativo se fez fecundo -, cabendo ao pesquisador a responsabilidade pela formatação final e construção da apresentação dele.

Assim, o projeto Gênero e Diversidade: construindo uma Escola Plural foi estruturado, reescrito, discutido e está em fase de implementação no lócus desde fevereiro do corrente ano [2019]. Destacamos, portanto, o papel da investigação sobre a temática de gênero e sexualidade na ressignificação do olhar para o outro e na corresponsabilização dos profissionais quanto aos seus discursos e práticas, fortalecendo sua agência neste processo de busca por soluções fundadas nos saberes compartilhados e construídos ao longo da pesquisa. 
Convidamos Aragão, Barros e Oliveira (2005) para, neste diálogo, finalizarmos nossas conclusões colaborativas: o pesquisador tal como um arqueólogo, ou tal como um cartógrafo, explora estratos teóricos com o intuito de encontrar os restos que, quando atualizados, possam imprimir um movimento de atualização aos estudos realizados.

Um arqueólogo não sabe exatamente o que vai encontrar, assim como um cartógrafo iniciante não sabia o que encontraria, nem como cartografaria o campo e território de pesquisa, a escola. Houve procura, muita procura e atenção aos detalhes, ao fugidio, às linhas de fuga para construção de um percurso como professor pesquisador sujeito que habita os territórios escolares hoje.

Pesquisar sobre gênero é transgredir, implica romper com as próprias barreiras e limites para construir saberes precários, pois fundados na experiência da diferença - transgredir identidades de gênero, identidades profissionais, desterritorializar-se é transpassar os lugares e papéis que nos foram atribuídos: isto porquê nossos corpos e gêneros, assim como de nossos alunos, são performativos e não respondem mais aos enquadramentos instituídos e fundados numa homogeneidade ilusória que se funda a partir da manutenção do outro como abjeto.

Problematizar as questões de gênero e transgredir as fronteiras da normatividade não é uma tarefa fácil no dentro e fora da escola, mas é convidativa e provocativa. É a partir desta pista deixada que esperamos encontrar outros pesquisadores dispostos a cartografar e transgredir o território da escola como lócus para debate e acolhimento das diversidades em suas diferenças e do debate de gênero e sexualidade como dimensão constitutiva das nossas performances de seres em constante atualização de suas potências e existências.

\section{REFERÊNCIAS}

ALVES, Nilda. Decifrando pergaminho: o cotidiano das escolas nas logicas das redes cotidianas. In: OLIVEIRA, Inês Barbosa de; ALVES, Nilda (Org.). Pesquisa no/do cotidiano das escolas: sobre redes de saberes. Petrópolis, Rio de Janeiro: DP, 2001. p.13-38

ARAGÃO, Elisabeth Maria; BARROS, Maria Elisabeth Barros de; OLIVEIRA, Sonia Pinto de Oliveira. Falando de metodologia de pesquisa. Revista Estudos e Pesquisas em Psicologia, RJ, UERJ, ano 5, n. 2, $2^{\circ}$ semestre de 2005. Disponível em: http://pepsic.bvsalud.org/pdf/epp/v5n2/v5n2a03.pdf. Acesso em: 20 set. 2018.

BELL, Hooks. Ensinando a transgredir: a educação como prática de liberdade; Tradução de Marcelo Brandão Cipolla. São Paulo: VMF Martins Fontes, 2013.

BENTO, Berenice Alves de Melo. 0 que é transexualidade? São Paulo: Brasiliense, 2008.

BOURDIEU, Pierre. A dominação masculina. Rio de Janeiro: Bertrand Brasil, 1999. 
BOZON, Michel. Les significations sociales des actes sexuels. Actes de la recherche en sciences sociales. Paris, n. 128, p. 3-23, jun. 1999.

BUTLER, Judith. Problemas de gênero: feminismo e subversão da identidade. Rio de Janeiro: Civilização Brasileira, 2016.

CANDAU, Vera Maria Ferrão (Org.). Reinventar a escola. 6. ed. Petrópolis, RJ: Vozes, 2008.

CANDAU, Vera Maria Ferrão. Diferenças culturais, interculturalidade e educação em direitos humanos. Revista Educação e Sociedade, Campinas, v. 33, n. 118, jan./mar., 2012. Disponível em: http://www.scielo.br/pdf/es/v33n118/v33n118a15.pdf. Acesso em: 12/02/2020

CANDAU, Vera Maria Ferrão; MOREIRA, Antônio Flávio. Educação escolar e cultura(s): construindo caminhos. Revista Brasileira de Educação, n. 23, p. 158-168, maio/jun./jul./ago. 2003.

CANEN, Ana. Multiculturalismo e formação docente: experiências narradas. Educação e Realidade, v. 24, n. 2, p. 89-102, 1999.

CANEN, Ana. Universos culturais e representações docentes: subsídios para a formação de professores para a diversidade cultural. Educação e Sociedade, n. 77, p. 207-227, 2001.

CONNEL, Robert W. Políticas da masculinidade. Educação e Realidade, São Paulo, v. 2, n. 4, p. 183-206, 1995.

DELEUZE, Gilles. 0 que é um dispositivo? 1996. Disponível em http://www.uc.pt/iii/ceis20/ conceitos_dispositivos/programa/deleuze_dispositivo.pdf. Acesso em: 6 ago. 2019.

DELEUZE, Gilles; GUATTARI, Félix. Mil platôs: capitalismo e esquizofrenia. V. 1. Rio de Janeiro: Ed. 34, 1995.

DELEUZE, Gilles; GUATTARI, Félix. Mil platôs: capitalismo e esquizofrenia. V. 2, Rio de Janeiro: Ed. 34, 1995. DESGAGNÉ, Serge. O conceito de pesquisa colaborativa: a ideia de uma aproximação entre pesquisadores universitários e professores práticos. Revista Educação em Questão, v. 29, n. 15, 2007.

FACIOLI, Lara. Aprendendo diferença: escola um espaço privilegiado para combater preconceitos. Revista de História da Biblioteca Nacional, ano 10, n. 119. ago. 2015.

FILHO, Roberto S. Teixeira. A educação sexual nos livros didáticos de Biologia: uma abordagem no campo do currículo. 2016. 126f. Dissertação (Mestrado Profissional em Educação e Diversidade) Universidade do Estado da Bahia, Jacobina, 2016. 
FILHO, Roberto S. Teixeira; SILVA, Ana Lúcia Gomes da. A abordagem da Educação Sexual nos livros didáticos de biologia. Colóquio Docência e Diversidade na Educação Básica: Políticas, práticas e formação, 2. Anais..., Salvador, 2015. Disponível em: https://drive.google.com/file/ d/0ByNLmv5aZLadYTJwLXFLaVoyNIU/view. Acesso em: abr. 2017

GARCIA, Wilton. Da performance à diversidade: estudos contemporâneos. In: COLLING, Leandro (Org.). Stonewall 40 + o que no Brasil? Salvador: EDUFBA, 2011.

IVENICK, Ana. Políticas educacionais e diversidade na escola: desafios da/na contemporaneidade. In: RIOS, Jane Adriana Vasconcelos Pacheco Rios (Org.). Políticas, práticas e formação na educação básica. Salvador: EDUFBA, 2015.

LOURO, Guacira Lopes. Gênero, sexualidade e educação: uma perspectiva pós-estruturalista. 16. ed. Petrópolis, RJ: Vozes, 2014.

MISKOLCI, Richard. Um aprendizado pelas diferenças. 2. ed. rev. e ampl., 3. reimp. Belo Horizonte: Autêntica Editora, 2016.

MOREIRA, Antônio Flávio; CANDAU, Vera Maria (Org.) Multiculturalismo: diferenças culturais e práticas pedagógicas. 2. ed. Petrópolis, RJ: Vozes, 2008.

NASSIF, Lourdes. A origem do “Ninguém solta a mão de ninguém”. Portal GGN. Disponível em: https://jornalggn.com.br/historia/a-origem-do-ninguem-solta-a-mao-de-ninguem-por-marcelomendonca/. Acesso em: 10 mar. 2019.

NETO, Daniel N. dos Santos; SILVA; Lucineide O.; SILVA, Ana Lúcia Gomes da. Pesquisas aplicadas no programa de Pós-graduação em Educação e Diversidade: educação inclusiva em pauta. Cadernos de Pós-graduação, São Paulo, v. 16, n. 1, p. 114-135, jan./jun. 2017.

PASSOS, Eduardo; BENEVIDES, Regina de Barros. A cartografia como método de pesquisaintervenção. In: PASSOS, Eduardo; KASTRUP, Virgínia; ESCÓSSIA, Liliana da (Org.). Pistas do método da cartografia: pesquisa-intervenção e produção de subjetividade. Porto Alegre: Sulina, 2015.

PÉREZ, Carmen Lúcia Vidal. Vozes, palavras, textos: as narrativas autobiográficas na formação de professoras-alfabetizadoras. 2002. Tese (Doutorado) - Faculdade de Educação Universidade de São Paulo, São Paulo, 2002.

RAGO, Margareth. Por uma educação libertária: o gênero na nova escola. In: BARBOSA, Raquel 
Leite Lazzari (Org.). Formação de educadores: desafios e perspectivas. São Paulo: Editora UNESP, 2003. p.479-490.

RIOS, Jane Adriana Vasconcelos Pacheco Rios (Org.). Políticas, práticas e formação na educação básica. Salvador: EDUFBA, 2015.

SILVA, Ana Lúcia Gomes da; COSTA, Váldina Gonçalves da Costa; PEREIRA, Diego Carlos Pereira. Formação de professores/as pesquisadores/as: contribuições e implicações do método cartográfico para as pesquisas em educação. Revista de Educação, Ciência e Cultura, Canoas, v. 23, n. 2, 2018. Disponível em: http://revistas.unilasalle.edu.br/index.php/Educacao. Acesso em: 20 jan. 2019.

SILVA, Ana Lúcia Gomes da; SOUZA, Izanete Marques; FILHO, Roberto Santos Teixeira. Educação e diversidade: os desafios das interseccionalidades, 2. Anais.... Disponivel em: http://www.apidic.uneb. br/cillaa/wp-content/uploads/ANAIS-II-SINBAIANIDADE-II-CILLAA1.pdf. Acesso em: 2 maio 2017.

SILVA, Ana Lúcia Gomes da; SOUZA, Izanete Marques; Teixeira FILHO, Roberto Santos; SÁ, Maria Roseli Gomes Brito de. Mestrado profissional: cenários e singularidades em intervenção na educação. Revista Plurais, Salvador, v. 1, n. 1, p. 59-71, jan./abr. 2016.

SILVA, Ana Lúcia Gomes da. Os desafios impostos pela universalização na educação básica: acesso, permanência e qualidade social. In: RIOS, Jane Adriana Vasconcelos Pacheco (Org.). Políticas, práticas e formação na educação básica. Salvador, BA: EDUFBA, 2015. 
1 Mestre em Educação e Diversidade , na Universidade do Estado da Bahia, no Campus IV de Jacobina; participa dos grupos de pesquisa Diversidade, formação, educação básica e discursos (DIFEBA). Possui duas especializações concluídas, uma em Docência no ensino superior presencial e ead pela Faculdade Regional de Filosofia, Ciências e Letras de Candeias, outra em Educação a distância pela Universidade do Norte do Paraná (UNOPAR); É Licenciado em História pela Universidade Norte do Paraná (2014). Atua como professor da educação básica desde 2011, lecionando atualmente no Colégio Estadual Necy Novais em Barro Alto. Atua também na referida instituição como Presidente do Colegiado Escolar. Além disso atua como coordenador pedagógico na Escola Márcia Maria de Carneiro Meccia em Barra do Mendes. E-mail: lucembergdo@hotmail.com

2 Pós-doutora em Educação pela Universidade Federal do Triângulo Mineiro (UFTM). Doutora em Educação pela Universidade Federal da Bahia (UFBA). Mestre em Educação pela Universidade Federal da Bahia (UFBA). Especialista em Leitura: Teoria e prática (UESB). Graduada em Letras Vernáculas (UNEB). Professora Titular do Departamento de Ciências Humanas - DCH/Jacobina da Universidade do Estado da Bahia (UNEB) da área de Prática Pedagógica, Estágio Supervisionado de Letras e Literaturas e Seminário Interdisciplinar de Pesquisa (SIP). Docente permanente do Programa de Pós- Graduação em Educação e Diversidade (PPED). Líder do Grupo de Pesquisa Diversidade, Formação, Educação Básica e Discursos - DIFEBA (UNEB). E-mail: analucias12@gmail.com

3 Doutora na área de Literaturas de Língua Portuguesa pelo Programa de Pós-Graduação em Letras da (PUC-MG). Mestre em Inglês: Estudos Linguísticos e Literários (UFSC). Graduação em Letras Português Inglês Licenciatura Plena (FECILCAM). Professora Adjunta do Departamento de Ciências Humanas - DCH/Jacobina da Universidade do Estado da Bahia (UNEB) de Letras Língua Inglesa e Literaturas. Docente permanente do Programa de Pós-Graduação em Educação e Diversidade (PPED) da Universidade do Estado da Bahia. Líder do Grupo de Pesquisa Diversidade, Formação, Educação Básica e Discursos - DIFEBA (UNEB) e do Desleituras em Série. E-mail: jsalvadoriuneb@gmail.com
Recebido em: 30 de Março de 2018

Avaliado em: 5 de Maio de 2018

Aceito em: 10 de Agosto de 2018
A autenticidade desse artigo pode ser conferida no site https://periodicos. set.edu.br

\section{Como citar este artigo:}

ROMEO, Andrea. Lo special account del fenomeno religioso nel dibattito nordamericano. Argumenta Journal Law, Jacarezinho - PR, Brasil, n. 29., 2018, p. 15-48. DOI: 10.17564/2316-3828.2018v7n1p13-24

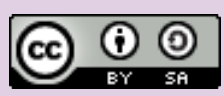

Este artigo é licenciado na modalidade acesso abertosob a Atribuição-Compartilhalgual CC BY-SA

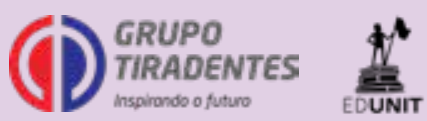

